\title{
The inter-regional epidemiological study of childhood cancer (IRESCC)* : a case control study of aetiological factors in leukaemia and lymphoma
}

\author{
P A MCKINNEY, R A CARTWRIGHT, J M T SAIU, J R MANN, C A STILLER, \\ G J DRAPER, A L HARTLEY, P A HOPTON, J M BIRCH, J A H WATERHOUSE, AND \\ H E JOHNSTON
}

Department of Epidemiology, Yorkshire Regional Cancer Organisation, Cookridge Hospital, Leeds, Department of Epidemiology and Social Research, Christie Hospital and Holt Radium Institute, Manchester, The Children's Hospital, Birmingham, West Midlands Cancer Registry, Queen Elizabeth Medical Centre, Birmingham, and University of Oxford, Childhood Cancer Research Group, Radcliffe Infirmary, Oxford

SUMMARY The inter-regional epidemiological study of childhood cancer analysed data on 234 children diagnosed with leukaemia or lymphoma and 468 controls matched for age and sex. A wide range of potential risk factors was examined, including prenatal exposure to $x$ rays, maternal drug ingestion and smoking, child's medical history, and parental medical conditions and occupation. Calculations were completed for leukaemia or lymphoma and diagnostic subgroups, as defined by laboratory confirmed cell type. In utero exposure to narcotic analgesics was weakly associated with leukaemia or lymphoma but no other antenatal factors gave significant risks. New associations were identified for skin diseases in both parents and congenital abnormalities in the mothers of children with leukaemia. For past medical conditions in the child, viral disease occurring under 6 months of age increased the risk for acute lymphoblastic leukaemia. Fewer children in the leukaemia or lymphoma group had been immunised compared with the control groups. Case children diagnosed over the age of 9 years were more likely than controls to have had four or more previous episodes of illness. Overall, these results indicate that prenatal factors may be less important than postnatal or genetic influences in the development of leukaemia or lymphoma in children.

In the United Kingdom data have suggested a rise in the incidence of childhood leukaemia. ${ }^{2}$ The reasons for this increase remain obscure, in parallel with the failure of epidemiological studies to detect any major risk factors for childhood leukaemia or lymphoma. Advances in immunophenotyping of haematologic malignancies now permit the identification of distinct subtypes of diseases once thought to be single entities. Hence aetiological investigation of accurately classified disease phenotypes can be accomplished. As yet few epidemiological studies have incorporated this approach, particularly for childhood reticuloendothelial neoplasms.

*IRESCC Group: the authors and Dr C C Bailey, Dr A H Cameron, Dr R H A Campbell, Dr S C Cartwright, Mr J J Corkery, Dr D Deakin, Mr P Gornall, Dr H B Marsden, Dr P H Morris-Jones, Dr D Pearson, Mr R Swindell, and Mrs J Williams.
The inter-regional epidemiological study of childhood cancer (IRESCC), a collaborative case control study, gathered a wide range of information from parents of 555 children diagnosed with childhood cancer and 1110 control children. The aim of this paper is to present the systematic evaluation of aetiological factors relating to the 234 cases of childhood leukaemia or lymphoma.

\section{Methods}

The study was conducted in three regional health authorities-Yorkshire, West Midlands, and North West. Cases of childhood malignancy were ascertained within these defined geographical areas from January 1980 to January 1983. Details of the case control methodology as applied to this study are described elsewhere. ${ }^{3}$ A total of 234 case children 
(under 15 years) diagnosed with leukaemia or lymphoma were included and their parents interviewed with a standard questionnaire. Each case child was matched for age and sex with two healthy control children selected from admissions to hospital and general practitioner lists. Identical information was gathered from the parents of these control children as had been gathered from the parents of the children with leukaemia or lymphoma. Questions asked for details of the index antenatal period (illness, investigations, drug ingestion, complications, smoking, and alcohol consumption), medical history of the child, parents, and other family members, and parental occupation and smoking habits. Additional data were abstracted from medical notes. In particular, efforts were made to see relevant obstetric notes for every case and control mother interviewed. For both parents and child, diseases and conditions not related to pregnancy were coded according to the International Classification of Diseases, ${ }^{4}$ apart from gynaecological problems, which had unique IRESCC codes. Social class was assessed according to the father's occupation at the time of the child's birth. ${ }^{5}$

An extensive range of risk factors was investigated for any possible association with childhood leukaemia or lymphoma. Preliminary tables for case control comparisons were produced using SPSS version X. ${ }^{6}$ Statistical analysis of cases versus pooled (hospital and general practitioner) controls was completed on a Hewlett Packard 41CV programmable calculator using the programs of Rothman and Boice. ${ }^{7}$ Relative risks were produced by the MantelHaenzsel method, with tests based on $95 \%$ confidence intervals and two tail $\mathrm{p}$ values. $\chi^{2}$ and $t$ tests were used when appropriate on certain variables.

\section{Results}

The distribution for sex and age at diagnosis of the 234 children with leukaemia or lymphoma who were interviewed is shown in Table 1 . They were not the complete set of incident cases from the three study regions because certain exclusions were made $^{3}$ for pragmatic reasons.

All 234 children with leukaemia or lymphoma had cytologically or histologically confirmed diagnoses. Of the 171 children with leukaemia, 148 were typed as acute lymphoblastic leukaemia, with common acute lymphoblastic leukaemia being confirmed by Professor M F Greaves in 78 patients. The 'other acute lymphoblastic leukaemia' group included diagnoses of uncertain cell origin, $T$ cell, $B$ cell, and null cell acute lymphoblastic leukaemia and 24 cases not submitted for cell typing, as detailed in Table 1 . Most of the other leukaemias were of myeloid
Table 1 Incidence of leukaemiallymphoma cell type by sex $(M=$ male; $F=$ female $)$ for age at diagnosis

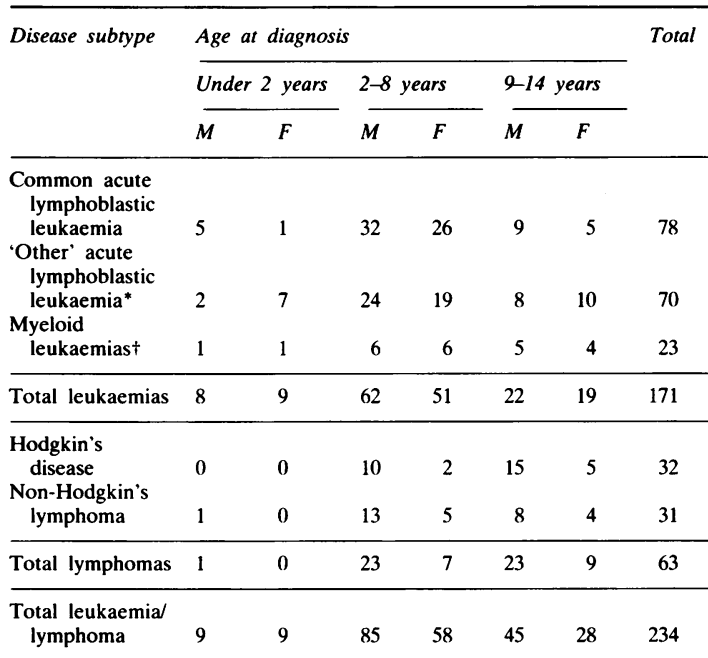

${ }^{*}$ Includes cases untested for cell type (24), T cell (10), B cell (two), and null cell acute lymphoblastic leukaemia (eight), and uncertain cell type (26). tIncludes acute myeloid leukaemia (18), chronic myeloid leukaemia (two), acute promyelocytic leukaemia (one), erythroleukaemia (one), and megakaryocytic leukaemia (one).

origin. The lymphomas (63 cases) were equally distributed between Hodgkin's disease (32 cases) and non-Hodgkin's lymphoma (31). The rationale for categorising the leukaemia or lymphoma was based on the hypothesis that varying cell types of disease may have differing aetiologies and laboratory confirmation of individual phenotypes permits investigation of homogeneous subgroups. Insufficient numbers necessitated grouping some cell types, though most of the untested cases of acute lymphoblastic leukaemia were probably of the common null cell type.

For many of the potential risk factors investigated, no significant case control differences emerged either for major diagnostic groups (leukaemia or lymphoma, leukaemias, and lymphomas) or smaller sized subgroups. Table 2 lists the factors examined that fell into this category, detailing the type of comparisons made. None of the relative risks were greater than 2 or reached significance at the $5 \%$ level.

Pregnancy and related events. Fetal exposure to potential carcinogens was investigated by close examination of the relevant antenatal period, using both interview reports and medical records. No obstetric notes were available, from either the general practitioner or the hospital, for a very small 
Table 2 Factors that failed to show any major positive* associations with childhood leukaemia or lymphoma

\section{Pregnancy and related events}

Interval between stopping oral contraception and conception (no gap or $<3$ months) $t$

Type of antenatal care (hospital or general practitioner practice, or both) Amniocentesis examination

General anaesthetic

Alcohol consumption

Duration of gestation

Type of delivery (normal, breech, assisted, or caesarean)

Place of delivery (home or hospital)

Maternal smoking (1-20 cigarettes a day, 21 or more cigarettes a day)

Infections during pregnancy (influenza, urinary tract infection)

Toxaemia

Threatened miscarriage

Ultrasound examinations

Birth and neonatal experiences

Apgar score at birth $(<5 v$ rest $)$

Breast fed

Length at birth

Birth weight $\ddagger$

Family factors

Maternal age $(<24$ years, $<20$ years, $<40$ years $)$

Paternal age $(<20$ years, $<40$ years $)$

Birth order (rank $1 v$ rest)

Sibship size (five or more sibs), excluding $1 / 2$ sibs

Father's social class (I, II, IIIN $v$ IIIM, IV, V)

Other factors

Fathers smoking (1-20 cigarettes a day. 21 or more cigarettes a day) Exposure to pets (for example, all mammals, cats, birds)

${ }^{*}$ That is, relative risks $<2$ and non-significant statistical tests

† Bracketed information indicates comparisons used in the analysis; otherwise nominal binary groups were used.

$\ddagger$ See text number of mothers-three cases of leukaemia or lymphoma and six general practitioner and three hospital controls. Antenatal factors apparently unrelated to the subsequent development of leukaemia or lymphoma are shown in Table 2. Birth weight was similar for cases and controls in the pooled diagnostic group (leukaemia and lymphoma) but for those in the lymphoma group the mean birth weight of cases and controls was significantly different. The case babies were lighter than their matched controls (mean birth weight for cases $3260 \mathrm{~g}$ and for controls $3433 \mathrm{~g}, \mathrm{p}=0.05, t$ test). This was accounted for by the babies with non-Hodgkin's lymphoma (cases $3194 \mathrm{~g}$, controls $3437 \mathrm{~g}, \mathrm{p}=0.05, t$ test).

Risks to the fetus of maternal drug ingestion were calculated, grouping drugs according to their pharmacological action. Table 3 shows the absence of any major transplacental carcinogenic effect for most drug groups apart from narcotic analgesics ingested in pregnancy and barbiturates taken during labour. The significant relative risk of 8.3 for the group with leukaemia or lymphoma with reported ingestion of narcotic analgesics was due to the leukaemia subgroup (seven cases (seven acute, none myeloid), one general practitioner control, one hospital control; relative risk $=7 \cdot 3,95 \%$ confidence intervals $1.9,28 \cdot 3 ; \mathrm{p}<0.01$ ), with medically prescribed narcotic analgesics approaching significance.

Table 3 Drugs ingested during index pregnancy and labour

\begin{tabular}{|c|c|c|c|c|c|c|}
\hline \multirow{2}{*}{\multicolumn{3}{|c|}{ Drug group }} & \multicolumn{4}{|c|}{ Estimated relative risk for leukaemias/lymphomas } \\
\hline & & & \multicolumn{2}{|c|}{ Reported at interview } & \multicolumn{2}{|l|}{ Medically recorded } \\
\hline \multicolumn{2}{|l|}{ Analgesics } & \multicolumn{3}{|c|}{0.9} & \multicolumn{2}{|l|}{$1 \cdot 3$} \\
\hline & \multirow{2}{*}{\multicolumn{3}{|c|}{$\begin{array}{l}1.0 \\
0.6\end{array}$}} & \multicolumn{2}{|l|}{$1 \cdot 0$} \\
\hline \multirow{2}{*}{\multicolumn{2}{|c|}{$\begin{array}{l}\text { Antifungals } \\
\text { Antihistamines }\end{array}$}} & & & & \multicolumn{2}{|l|}{0.7} \\
\hline & & \multicolumn{3}{|c|}{$1 \cdot 3$} & \multicolumn{2}{|l|}{$1 \cdot 1$} \\
\hline \multicolumn{2}{|c|}{$\begin{array}{l}\text { Antihistamines } \\
\text { Barbiturates (pregnancy only) }\end{array}$} & \multicolumn{3}{|c|}{$1 \cdot 0$} & \multicolumn{2}{|l|}{$1 \cdot 0$} \\
\hline \multicolumn{2}{|c|}{ Benzodiazepines } & \multicolumn{3}{|c|}{0.7} & \multicolumn{2}{|l|}{0.9} \\
\hline \multicolumn{2}{|l|}{ Diuretics } & \multirow{2}{*}{\multicolumn{3}{|c|}{$1 \cdot 0$}} & \multicolumn{2}{|l|}{1.4} \\
\hline \multicolumn{2}{|l|}{ Hormones } & \multicolumn{2}{|r|}{0.9} & & \multicolumn{2}{|l|}{0.7} \\
\hline \multicolumn{2}{|c|}{ Hormone confirmation of pregnancy } & \multirow{2}{*}{\multicolumn{3}{|c|}{0.8}} & \multirow{2}{*}{\multicolumn{2}{|c|}{$\begin{array}{l}1.2 \\
0.6\end{array}$}} \\
\hline \multirow{2}{*}{\multicolumn{2}{|c|}{$\begin{array}{l}\text { Topical steroids } \\
\text { Phenothiazines (major tranquilisers) }\end{array}$}} & & & & & \\
\hline & & \multicolumn{3}{|c|}{$\begin{array}{l}1 \cdot 0 \\
2 \cdot(0)\end{array}$} & 1.5 & \\
\hline \multicolumn{7}{|c|}{ Drug groups with significant associations } \\
\hline Drug group & $\begin{array}{l}\text { Diagnostic group } \\
\text { (No of cases) }\end{array}$ & \multicolumn{2}{|c|}{$\begin{array}{l}\text { Reported at interview } \\
\text { or medically recorded }\end{array}$} & Relative risk & $\begin{array}{l}95 \% \text { Confidence } \\
\text { intervals }\end{array}$ & p Value \\
\hline \multirow{4}{*}{$\begin{array}{l}\text { Narcotic analgesics } \\
\text { (during pregnancy) }\end{array}$} & Leukacmia/lymphoma & \multirow{2}{*}{\multicolumn{2}{|c|}{ Reported at interview }} & $8 \cdot 3$ & $2 \cdot 2,30 \cdot 7$ & $<0 \cdot 01$ \\
\hline & (234) & & & $1 \cdot 4$ & $0.7, \quad 2 \cdot 7$ & 0.29 \\
\hline & Leukacmias & Reported at & intervicw & $7 \cdot 3$ & $1.9,28 \cdot 3$ & $<0 \cdot 01$ \\
\hline & $(171)$ & Medically re & ecorded & 2.0) & $1.0 . \quad 4.0$ & 0.06 \\
\hline Barbiturates (in labour) & $\begin{array}{l}\text { Leukaemia/lymphoma } \\
(234)\end{array}$ & Medically re & ecorded & $5 \cdot 5$ & $1 \cdot 7,18 \cdot 1$ & $<0 \cdot(01$ \\
\hline & $\begin{array}{l}\text { Leukacmias } \\
(171)\end{array}$ & Medically $\mathrm{re}$ & ecorded & $3 \cdot 0$ & $0 \cdot 6,16 \cdot 9$ & $0 \cdot 20$ \\
\hline & $\begin{array}{l}\text { Lymphomas } \\
(63)\end{array}$ & Medically re & ecorded & $10 \cdot 8$ & $1 \cdot 8,63 \cdot 2$ & $<0.01$ \\
\hline
\end{tabular}


For medically recorded ingestion of narcotic analgesics 15 case children exposed in utero were diagnosed, seven with common null cell acute lymphoblastic leukaemia, seven with acute lymphoblastic leukaemia, and one with myeloid leukaemia. Dextropropoxyphene hydrochloride (Distalgesic) was the commonest narcotic analgesic used and similar reasons were given by case and control mothers for its usage. Drugs administered during labour were recorded only from medical notes. A significantly raised relative risk of 5.5 for barbiturates in the group with leukaemia or lymphoma was due to excessive numbers in the lymphoma subgroup (five cases (two Hodgkin's disease, three nonHodgkin's lymphoma), one general practitioner control, no hospital control; relative risk $=10 \cdot 8,95 \%$ confidence intervals $1 \cdot 8,63 \cdot 2 ; \mathrm{p}<0.01$ ).

In utero exposure to $x$ rays was analysed using data from medical notes, counting direct fetal exposure from abdominal/pelvic $x$ rays, and using pelvimetry. Ninety five per cent of pelvic films taken were in the third trimester for cases and controls. Reasons given for the prescription of giving $x$ rays included suspicion of multiple pregnancy, fetal abnormality or presentation, 'checking dates'/ determining maturity, and a single instance of 'confirmation of engaged fetal head'. The relative risks for pelvic radiography were all greater than unity but not significant. Stratifying the 'pelvic' group by age at diagnosis gave seven cases, three general practitioner controls, and two hospital controls exposed in the group with leukaemia or lymphoma diagnosed under 2 years of age (relative risk $=3.4,95 \%$ confidence intervals $0.9,12.9$; $p=0.07)$. The referent category of mothers had received no $x$ rays of any type-for example, chest $x$ rays. No risk for any other age reached significance.

Illnesses in parents. The medical history of the index child's mother and, where possible, father was recorded at interview. Attempts were made to confirm medically congenital abnormalities, cancers, and chronic diseases. The medical histories of the fathers and mothers of the index children did not differ significantly from those of the controls with regard to musculoskeletal and connective tissue disorders (ICD9 710-739), central nervous system disorders (ICD9 320-349), mental disorders (ICD9 290-319), or respiratory system diseases (ICD9 460-519). For skin diseases (ICD9 680-709), however, significant relative risks were present within the major diagnostic groups for both parents (Table 4). There was only one case of both parents of a case child having a skin condition. Medically recorded data showed a case excess for the leukaemias (fathers: eight cases, three general practitioner

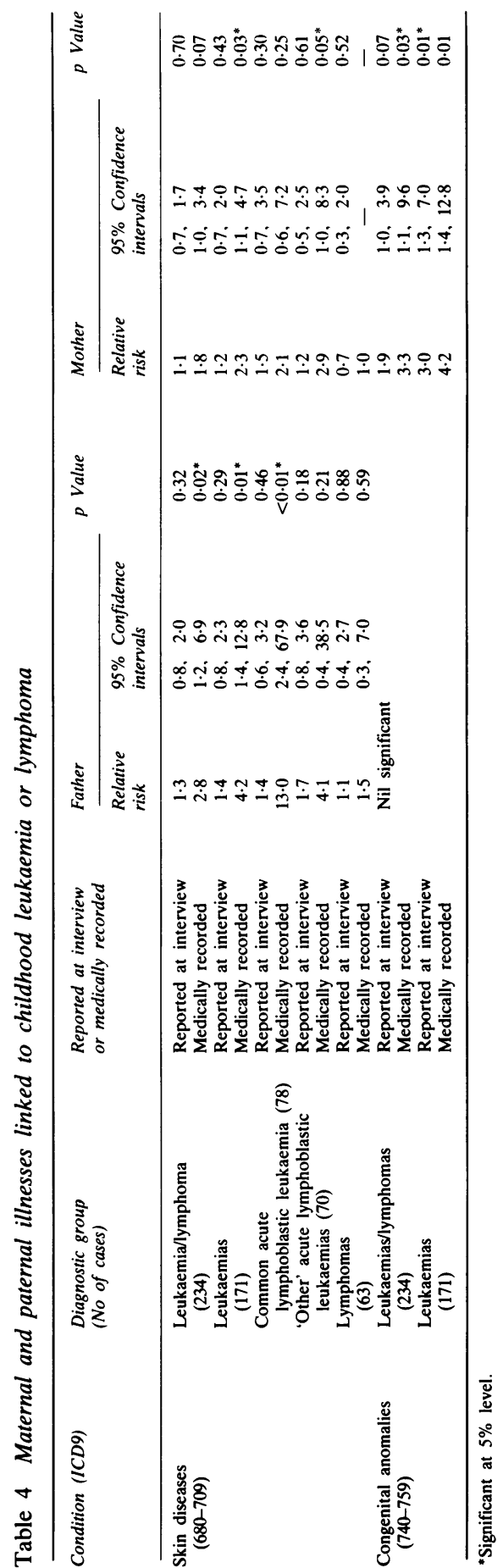


controls, one hospital control; mothers: 15 cases, four general practitioner controls, 10 hospital controls), accounted for by the common null cell and other acute lymphoblastic leukaemia subgroups in the fathers and mothers, respectively. Confining the analysis to eczema/dermatitis conditions (ICD9 690698) resulted in a non-significant case excess for both parents in the leukaemia or lymphoma group (fathers: five cases, four general practitioner controls, one hospital control; mothers: 11 cases, four general practitioner controls, 12 hospital controls). Congenital anomalies (ICD9 740-759) occurred more often in case mothers, particularly those with children with leukaemia (interview reports: 13 cases, two general practitioner controls, seven hospital controls; medical records: eight cases, one general practitioner control, three hospital controls). Estimated relative risks are shown in Table 4. Much of the excess was due to ICD9 757.9-mainly nonspecific birthmarks. Case control comparisons for all diagnostic groups gave no increased risk for the following gynaecological conditions occurring either before or after the index pregnancy: fibroids, cysts and polyps of the genital tract, infertility, and menorrhagia.

Child's medical history. Details of congenital anomalies, chronic disease, and childhood illnesses were obtained for the index child, but medical confirmation was sought routinely only for major congenital abnormalities and chronic diseases. Case control comparisons were made for respiratory system diseases (ICD9 460-519), central nervous system disorders (ICD9 320-349), and skin diseases (ICD9 680-709), but large numbers of reported conditions were of a non-specific nature. No case control differences were evident for these conditions.
Viral diseases (ICD9 045-079, 408), comprising chickenpox, rubella, measles, mumps, viral meningitis, and viral influenza, were recorded at interview if the episodes occurred when the child was under 6 months of age. In the group with leukaemia or lymphoma a significantly increased number of case children were noted to have had viral illnesses (Table 5). This was accounted for particularly by the common null cell acute lymphoblastic leukaemia and lymphoma subgroups (Table 6). No significant differences were present for respiratory system disorders or skin diseases diagnosed under 6 months of age. Children with viral disease in the six months before diagnosis were excluded from analysis. Reports of early viral diseases were proportionately distributed between the three regions that contributed data.

Analysis of the total number of episodes of illness for each child revealed that case children had an increased frequency of diseases compared with controls. Comparing a history of three or less instances with four or more, risks approached and reached significance for reported and medically recorded data, respectively, in the group with leukaemia or lymphoma (Table 5). The children with leukaemia accounted for the reported excess, with the children with lymphoma showing a significant risk for medically recorded illness due to three cases of non-Hodgkin's lymphoma and no controls. On stratification by age at diagnosis (under 2 years, 2-8 years, and 9-14 years) a significant excess was shown only in the 9-14 age group.

Table 5 also shows that for the group with leukaemia or lymphoma and the leukaemia subgroup, more case than control children failed to receive their usual vaccinations (leukaemia or lymphoma: six cases, no general practitioner

Table 5 Risk factors in index child's medical history

\begin{tabular}{|c|c|c|c|c|c|}
\hline Risk factor & $\begin{array}{l}\text { Diagnostic group) } \\
\text { (No of cases) }\end{array}$ & $\begin{array}{l}\text { Relative } \\
\text { risk }\end{array}$ & $\begin{array}{l}95 \% \text { Confidence } \\
\text { intervals }\end{array}$ & p Value & $\begin{array}{l}\text { Reported at interview or } \\
\text { medically recorded }\end{array}$ \\
\hline $\begin{array}{l}\text { Viral disease* (ICD9 }(045-1) 79 . \\
480) \text { under } 6 \text { months of age }\end{array}$ & Leukacmia/lymphoma (234) & $4 \cdot 1$ & $1 \cdot 5 \cdot 11 \cdot 3$ & $<0 \cdot(0)$ & Reported at interview \\
\hline \multirow[t]{4}{*}{ Immunisations } & Leukaemia/lymphoma (234) & $0 \cdot 3$ & $0.1, \quad 1.1$ & 0.117 & Reported at interview \\
\hline & Leukaemias (171) & $0 \cdot 2$ & $(1.1 . \quad 0.9$ & $0.1(1) .3$ & Reported at interview \\
\hline & Myeloid leukaemias (23) & $(1) \cdot 1$ & $0.0 . \quad 1.0$ & 0.155 & Reported at interview \\
\hline & Lymphomas (63) & $1 \cdot 0$ & $0.1,11 \cdot 5$ & 0.99 & Reported at interview \\
\hline \multirow{6}{*}{$\begin{array}{l}\text { No of episodes of illness } \\
\text { per child } \ddagger(<4 v \geqslant 4)\end{array}$} & Leukacmia/lymphoma (234) & 1.6 & $0.1, \quad 2.7$ & 0.06 & Reported at interview \\
\hline & & $2 \cdot 4$ & $1.1 . \quad 4.9$ & 0.12 & Medically recorded \\
\hline & Leukaemias (171) & 1.9 & $1 \cdot(1) \quad 3 \cdot 4$ & 0.14 & Reported at interview \\
\hline & & 1.6 & $0.5,5.0$ & $11 \cdot 46$ & Medically recorded \\
\hline & Lymphomas (6.3) & $1 \cdot 1$ & $0.4, \quad 3 \cdot 1$ & 0.81 & Reported at interview \\
\hline & & $5 \cdot 7$ & $1 \cdot 2.27 \cdot 1$ & $(1.1) 3$ & Medically recorded \\
\hline
\end{tabular}

*Excludes cases with viral diseases in the six months before diagnosis (and for controls pseudodiagnosis)

tExcludes cases diagnosed under 1 year of age.

Exposed children are those given one or more of tetanus, diphtheria, whooping cough. smallpox. polio, measles, or triple vaccination.

†ncludes all ICD9 coded illness, excluding congenital anomalies.

Study protocol did not attempt to confirm viral disease and immunisations. 
284 McKinney, Cartwright, Saiu, et al

Table 6 Viral diseases occurring under 6 months of age

\begin{tabular}{|c|c|c|c|}
\hline Case diagnosis & Cell type & Disease & $\begin{array}{l}\text { Time interval (disease to } \\
\text { diagnosis) (years) }\end{array}$ \\
\hline \multicolumn{4}{|l|}{ Cases } \\
\hline Acute lymphoblastic leukaemia & Common & Chickenpox & 5 \\
\hline Acute lymphoblastic leukaemia & Common & Chickenpox & 4 \\
\hline Acute lymphoblastic leukaemia & Common & Viral meningitis & $2 \cdot 5$ \\
\hline Acute lymphoblastic leukaemia & Common & Rubella & $2 \cdot 5$ \\
\hline Acute lymphoblastic leukaemia & 'Other' & Measles & $5 \cdot 5$ \\
\hline Myeloid leukaemia & - & Rubella & $14 \cdot 5$ \\
\hline Non-Hodgkin's lymphoma & Not known & Viral influenza & 6 \\
\hline Non-Hodgkin's lymphoma & Not known & Measles & $7 \cdot 3$ \\
\hline Non-Hodgkin's lymphoma & Not known & $\left.\begin{array}{l}\text { 'Bronchial' virus } \\
\text { Rubella }\end{array}\right\}$ & $4 \cdot 5$ \\
\hline Hodgkin's disease & - & Mumps & 13 \\
\hline \multicolumn{4}{|l|}{ General practitioner controls } \\
\hline Acute lymphoblastic leukaemia & Common & Measles & $4 \cdot 5$ \\
\hline \multicolumn{4}{|l|}{ Hospital control } \\
\hline Acute lymphoblastic leukaemia & Common & Rubella & $2 \cdot 5$ \\
\hline Acute lymphoblastic leukaemia & 'Other' & Measles & 10 \\
\hline Acute lymphoblastic leukaemia & 'Other' & $\left.\begin{array}{l}\text { Chickenpox } \\
\text { Measles }\end{array}\right\}$ & 11 \\
\hline Acute lymphoblastic leukaemia & Untested & Viral infection (unspecified) & 3.5 \\
\hline
\end{tabular}

Table 7 Parental occupation

Mother

No associations with textile or clothing workers, any factory related occupation, clerical or sales workers, electronic/electrical workers, or professional technical workers

Father

\begin{tabular}{|c|c|}
\hline Occupations lacking major associations & Possible risk occupations \\
\hline $\begin{array}{l}\text { Miners/quarrymen } \\
\text { Gas, coke, and chemical workers } \\
\text { Electricalelectronic workers } \\
\text { Engineering } \\
\text { Woodworkers } \\
\text { Paper and printing workers } \\
\text { Painters and decorators } \\
\text { Drivers } \\
\text { Transport and communication workers } \\
\text { Service, sport, and recreation workers } \\
\text { Administrators and managers } \\
\text { Professional and technical workers } \\
\text { Armed forces } \\
\text { Farmers, foresters, and fishermen } \\
\text { Food, drink, and tobacco workers } \\
\text { Sales workers }\end{array}$ & $\begin{array}{l}\text { Furnacelforge/foundry workers } \\
\text { Leukaemia/lymphoma: relative risk } 4 \cdot 8 ; 95 \% \text { confidence intervals } 1 \cdot 4,16 \cdot 5 \text {. } \\
\text { Lymphomas: } 4 \text { cases. } 0 \text { controls } \\
\text { Textile workers } \\
\text { Lymphomas: relative risk } 8 \cdot 5 ; 95 \% \text { confidence intervals } 1 \cdot 3,55 \cdot 1 \text {. } \\
\text { Hodgkin's disease } 2 \text { cases, } 1 \text { control. } \\
\text { Non-Hodgkin's lymphoma } 2 \text { cases, } 0 \text { controls } \\
\text { Construction workers } \\
\text { Common acute lymphoblastic leukaemia: relative risk } 2 \cdot 9 ; 95 \% \text { confidence } \\
\text { intervals } 1 \cdot 2.7 \cdot 5 \text {. }\end{array}$ \\
\hline
\end{tabular}

controls, four hospital controls; leukaemia: five cases, no general practitioner controls, two hospital controls). Children diagnosed under 1 year of age were excluded from these calculations.

Parental occupation. No maternal occupation, with sufficient numbers to allow analysis, was associated with any major risk of childhood reticuloendothelial malignancy. Table 7 shows that there was a case excess of fathers who were furnace/forge and foundry workers, textile workers, and construction workers for certain diagnostic subgroups.

\section{Discussion}

Children diagnosed with leukaemia or lymphoma included in the IRESCC have previously been shown to be representative of this disease group within the UK. ${ }^{3}$ The case distribution shows a typical age peak in the 2-8 year olds for acute lymphoblastic leukaemia, an absence of Hodgkin's disease in the under $2 \mathrm{~s}$, and overall male predominance, particularly in the lymphomas subgroup. Roughly half of the acute lymphoblastic leukaemia subgroup were immunologically subtyped as con- 
firmed common null cell type. This aspect of our investigation was an important one, linking laboratory evidence of distinct disease entities with epidemiological methods investigating aetiological factors, an approach recommended in the light of recent developments in laboratory techniques. ${ }^{8}$

A variety of possible risk factors for leukaemia or lymphoma in children have previously been investigated, but few clear cut associations have emerged, an exception being in utero exposure to $x$ rays. ${ }^{9}{ }^{10}$ Our study results support these findings, specifically showing an increased risk (relative risk 3.4) for leukaemia or lymphoma diagnosed under 2 years of age. Reduction of significance in the present analysis compared with previous data ${ }^{11}$ can be explained, firstly, by differences in the assignment of controls. In the original letter controls with histiocytosis $\mathrm{X}$ were not excluded from the stratified analysis. Secondly, the total number of cases with leukaemia or lymphoma was reduced from 245 to 234 by removal of the nine cases with histiocytosis $\mathrm{X}$ (six diagnosed under 2 years) and two instances where diagnostic review resulted in recategorisation from the group with leukaemia or lymphoma. The results expressed in this $x$ ray analysis follow the stratified format adopted throughout the paper, and although the relative risk for $x$ rays is still high for the group with leukaemia or lymphoma, the smaller numbers in the cells fail to achieve significance.

Any drug ingested during pregnancy has the potential to cross the placenta, presenting a hazard to the developing fetus. Firm data on carcinogenic risks of antenatal drug use, particularly with reference to childhood leukaemia or lymphoma, are sparse. Sedatives and hormones taken during pregnancy have been claimed to convey increased risk of leukaemia ${ }^{12}$ and all childhood cancers, ${ }^{13}$ but this was not corroborated by our analysis. Direct comparison between studies is difficult as the systematic evaluation of pharmacological drug groups in our study used carefully defined categories ${ }^{14}$ not evident elsewhere in the published reports. For example, it is difficult to understand the term 'sedative'. ${ }^{12}$ An excess of case mothers took narcotic or opioid analgesics (mostly Distalgesic), an association reaching significance only for the information given at interview and not found for 'euphoriant analgesics' in another study. ${ }^{15}$ Ingestion of the drug was not allied to any particular condition, suggesting that the drug accounts for the association. Over reporting by case mothers could explain our observation but seems unlikely in the absence of positive links for other drug groups. A single significant association among multiple comparisons, however, may well be fortuitous. A stronger link can only be established by further testing of this new finding.
According to medical records, barbiturates were administered during labour to more mothers of children with lymphoma than to the mothers of the matched controls. This association was lost when barbiturates at any time during the index pregnancy were examined, making them unlikely transplacental carcinogens.

This study gathered detailed information on the medical history of both parents. Analysis of ICD9 coded groups showed no case excesses in any category except for mothers and fathers with skin diseases, where the association was most prominent for acute lymphoblastic leukaemia. No particular condition was more prevalent for either parent and it is of interest that maternal and paternal links existed. These findings are unique and require corroboration from other independent studies. A Yorkshire case control study of adult leukaemia and lymphoma found a case excess of skin disease in the patients themselves. ${ }^{16} \mathrm{We}$ are unable to hypothesise a causal explanation, although skin diseases may well be markers of some other associated inherited factor, such as a malfunctioning immune system. The frequency of congenital anomalies in the parents of children with leukaemia or lymphoma has not been previously reported and the significant excess of mothers, mainly in the group with leukaemia, is of interest but as yet inexplicable.

A striking finding from our data on the leukaemia or lymphoma group was the significant relative risk for contracting a viral disease under the age of 6 months. The development of leukaemia or lymphoma has long been linked to malfunctioning immunity, and the maturing neonatal immune system requires time to develop active immunity in response to antigenic stimulation, making early exposure to disease particularly relevant. Based on this idea we recorded all instances of infections under the age of 6 months. No case excess was found for any disease occurring after 6 months and the significance of viral exposure at a younger age was limited to the pooled leukaemia or lymphoma group. The latent period between viral exposure and malignancy ranged from 2.5 to 5.5 years for cases of acute lymphoblastic leukaemia; numbers in other groups were small, ranging from 4.5 to 14.5 years. For acute lymphoblastic leukaemia, the minimum gap of 2.5 years makes it unlikely that the viral disease was expressed due to intrinsic immunosuppression in the preclinical phase of malignancy, which Stewart estimated as one year. ${ }^{17}$ The rarity of both leukaemia or lymphoma in childhood and viral disease under 6 months means that our risk estimates are based on small numbers. In contrast, one study has shown that children with leukaemia have fewer infections in the first year of life ${ }^{18}$ Further conflict is 
apparent from our own data, where an excess of case children were not immunised. Small numbers make this apparent protective effect of immunisation an unreliable observation, although another recent and larger study had similar findings. ${ }^{19}$ The role the immune system plays in haematopoietic malignancies is unclear, and our association with early viral disease may be independent of immune regulation and effect malignant transformation through another route.

The association between childhood leukaemia or lymphoma and increased episodes of previous illness could be explained by over reporting by mothers of cases or under reporting by control mothers. This, however, seems unlikely because the case control differences are present for both interview reports and medically recorded conditions. Also the fact that the effect was strongest in the 9-14 age group is evidence against over reporting by case mothers. It was impossible in this study to assign the excess to one particular disease group or to determine whether any conditions were related to a susceptible period before diagnosis.

Parental occupation is a commonly investigated link with childhood cancer. A recent review article clearly showed the conflicting nature of results from previous studies. ${ }^{20}$ Our findings gave no indication of any risk occupations for the mother during the index pregnancy or before conception. For leukaemia, other studies have shown increased risk in association with hydrocarbon and chemical related occupational exposure during pregnancy ${ }^{21}$ and with mothers who were pharmacists. ${ }^{22}$ Hydrocarbon related paternal occupations have been positively $^{23-25}$ or equivocally ${ }^{26-29}$ linked to childhood leukaemia or lymphoma. Our finding of furnace/forge and foundry workers as a risk occupation for the group with leukaemia or lymphoma was accounted for by the lymphoma subgroup. Measurements of potential carcinogenic exposure within a working environment are generally unevaluable, and biologically plausible links with childhood cancer may be tenuous. Textile workers and construction workers were weakly linked to lymphomas and common null cell acute lymphoblastic leukaemia, respectively, relations that are also unsupported in previous publications.

Of broader interest is the documented increase in risk for children with leukaemia or lymphoma of parents in higher social classes, ${ }^{28} 30.31$ although our study and some others have failed to provide corroboration. $^{291}$ World wide, childhood acute lymphoblastic leukaemia seems to be a disease associated with improved living standards, ${ }^{32}$ although comparisons are relative and smaller socioeconomic differences will exist within the UK population.

Overall, results from this major epidemiological study have shown few aetiological factors positively linked to childhood leukaemia or lymphoma. The definition of diagnostic subgroups by cell type failed to clarify the picture or identify particular risk factors or susceptible children, but small numbers were a significant disadvantage in the more detailed analyses. The general lack of associations for prenatal factors suggests that postnatal exposures may possibly be of greater importance in the aetiology of childhood leukaemia or lymphoma. Possible genetic influences have not been explored in this paper but will be addressed in more detail in the future.

We thank the parents of the children included in the study and the many general practitioners, consultants, and nurses in the three regions who helped us. Also the Cancer Research Campaign, the Leukaemia Research Fund, the Department of Health and Social Services, the Scottish Home and Health Department, the Special Trustees for the former United Birmingham Hospitals Trust Funds, and the Special Trustees of Leeds Western Health Authority are thanked for financial support. We thank Dr H G Frank. Dr E Hill, and many other paediatricians. surgeons, and radiotherapists whose patients were included and the medical records officers and cancer registries in the three regions for their help. We thank Dr D I K Evans, Dr F G H Hill, and Professor M F Greaves for hacmatological confirmation of diagnoses, the Office of Population Censuses and Surveys for access to death certificates. Mrs P Brown, Mrs C Christmas, Mrs P Dilworth, Miss C Kite, Miss F M Landells, Mrs $\mathrm{H}$ Lilley, Mrs A Mainwaring, Miss G Mason, Mrs J Olden, Dr M Potok. Mrs E M Roberts, and Mrs S Warner for secretarial, statistical, and computing help. Rank Xerox for photocopying. Bell and Howell for the use of a microfilming camera, Systime Ltd for the gift of a computer, and the University of Leeds for the use of the Amdahl computer.

\section{References}

' Birch JM. Swindell R, Marsden HB, Morris-Jones PH. Childhood leukaemia in north west England 1954-1977: epidemiology, incidence and survival. Br J Cancer 1981:43:324-9.

2 Stiller CA. Descriptive epidemiology of childhood leukacmia and lymphoma in Great Britain. Leuk Res 1985;9:671-4.

'Birch JM, Mann JR, Cartwright RA, et al. The inter-regional epidemiological study of childhood cancer (IRESCC): study design, control selection and data collection. Br J Cancer 1985:52:912-22.

+ World Health Organisation. International classification of diseases. 9th revision, 1975. Geneva: WHO, 1978.

5 Office of Population Censuses and Surveys. Classification of occupations 1970. London: HMSO, 1970.

- SPSS version $X$ user's guide. New York: McGraw-Hill, 1985

7 Rothman KJ, Boice JD. Epidemiologic analysis with a programmable calculator. Boston, Massachusetts: Epidemiology Resources Inc, 1982.

× Magrath IT, O'Conor GT, Ramot B, eds. Pathogenesis of leukaemias and lymphomas: environmental influences. $\mathrm{New}$ York: Raven Press, 1984.

"Bithell JF, Stewart AM. Pre-natal irradiation and childhood malignancy. A review of British data from the Oxford survey. Br J Cancer 1975:31:271-87.

16) Monson R, MacMahon B. Prenatal x-ray exposure and cancer in 
children. In: Boice JD, Fraumeni JF. Radiation carcinogenesis: epidemiology and biological significance. New York: Raven Press, 1984:97-105.

$"$ Hopton PA, McKinney PA. Cartwright RA, et al. X-rays in pregnancy and the risk of childhood cancer. Lancet 1985;ii:773.

12 Van Steensel-Moll HA, Valkenburg HA, Vandenbroucke JP, van Zanen GE. Are maternal fertility problems related to childhood leukaemias. Int J Epidemiol 1985:14:555-60.

13 Kinnier-Wilson LM. Kneale GW, Stewart AM. Childhood cancer and pregnancy drugs. Lancet $1981 ;$;i:314-5.

14 McKinney PA. An examination of antenatal factors in the aetiology of childhood malignancies. Leeds: Leeds University, 1986. 239 pp. (PhD thesis.)

15 Salonen T. Prenatal and perinatal factors in childhood cancer. Ann Clin Res 1976;7:27-42.

${ }^{16}$ Bernard SM, Cartwright RA, Bird CC, Richards IDG, Lauder I, Roberts BE. Aetiologic factors in lymphoid malignancies: a case-control epidemiological study. Leuk Res 1984;8:681-9.

17 Stewart AM. Childhood cancers and the immune system. Cancer Immunology Immunotherapy 1980;9:11.

18 Van Steensel-Moll HA. Childhood leukaemia in the Netherlands, a register based epidemiological study. Rotterdam: University of Rotterdam, 1983. 155 pp. (MD thesis.)

19 Kneale GW, Stewart AM, Kinnier-Wilson LM. Immunizations against infectious diseases and childhood cancers. Cancer Immunology Immunotherapy 1986:21:129-32.

20) Arundel SE, Kinnier-Wilson LM. Parental occupations and cancer: a review of the literature. J Epidemiol Community Health 1986:40:30-6.

21 Van Steensel-Moll HA, Valkenburg HA, van Zanen GE. Childhood leukaemia and parental occupation: a register based case control study. Am J Epidemiol 1985;121:216-24.

22 Hemminki K, Saloniemi I, Salonen T, Partanen T, Vainio H. Childhood cancer and parental occupation in Finland. J Epidemiol Community Health 1981:35:11-5.
${ }^{23}$ Fabia J, Thuy TD. Occupation of father at time of birth of children dying of malignant diseases. British Journal of Preventative and Social Medicine 1974;28:98-100.

${ }^{24}$ Hakulinen T, Salonen T. Teppo L. Cancer in the offspring of fathers in hydrocarbon-related occupations. British Journal of Preventative and Social Medicine 1976;30:138-40.

${ }^{25}$ Gold EB, Diener MD, Szklo M. Parental occupations and cancer in children. $J$ Occup Med 1982;24:578-84.

${ }^{26} \mathrm{Kwa}$ SL, Fine LJ. The association between parental occupation and childhood malignancy. J Occup Med 1980;22:792-4.

27 Zack M, Cannon S, Lloyd D, et al. Cancer in children of parents exposed to hydrocarbon related industries and occupations. Am J Epidemiol 1980;111:329-36.

${ }^{28}$ Sanders BM, White GC. Draper GJ. Occupations of fathers of children dying from neoplasms. J Epidemiol Community Health 1981;35:245-50.

${ }^{29}$ Shaw G, Laney R, Jackson R, Austin D. Association of childhood leukaemia with maternal age, birth order and parental occupation. Am J Epidemiol 1984;119:788-95.

30 McWhirter WR. The relationship of incidence of childhood lymphoblastic leukaemia to social class. $\mathrm{Br} J$ Cancer 1982;46:640-5.

${ }^{31}$ Fasal E, Jackson EW, Klauber MR. Birth characteristics and leukaemia in childhood. Journal of the National Cancer Institute 1971:47:501-9.

${ }^{32}$ Greaves MF, Pegram SM, Chan LC. Collaborative group study of the epidemiology of acute lymphoblastic leukaemia subtypes: background and first report. Leuk Res 1985;9:715-33.

Correspondence to Dr R A Cartwright, Department of Epidemiology, Yorkshire Regional Cancer Organisation, Cookridge Hospital, Leeds LS16 6OB, England.

Received 15 September 1986 


\section{Book reviews}

each dysplasia and helpful cross references in the index-for example. on bow legs. cone shaped vertebral bodies, or short metacarpals. The clinical photographs. growth charts, and comparison of $x$-rays of-for example-hands or pelvis at similar and differing ages in different patients emphasise the astonishing variety in each dysplasia.

All who are puzzled by problems of failure to grow or short stature will be grateful to the authors for sharing their long and profound experience with those of us who see but a few patients. Their Mrs Beeton of bone dysplasia will amplify the standard references-Spranger, Langer. and Weidman's Bone Dysplasias and Smith`s Recognisable Patterns in Human Malformation.

Alas, there is a problem. Some of the illustrations do not show what their captions declare, particularly the infant's skulls and lateral spines: perhaps these can be improved in the next edition. It is a pity too that there are no captions beneath the introductory normal $x$-rays. Why no mention of idiopathic bow legs under metaphyseal dysplasia? Do the authors still advise babygrams? It would have been helpful to have a list of conditions diagnosable at birth.

But one likes a friend better for having faults one can talk about; I can enthusiastically welcome this book and recommend it to all paediatricians. A Mrs Beeton with four eggs, a rich diet indeed but digestible.

SIDNEY SMITH

Sonography of the Infant Hip: an Atlas. By Reinhard Graf and Peter Schuler. Pp 276: DM150 hardback. VCH Verlagsgesellschaft. 1986

One of the initial troubles with ultrasound examinations is the difficulty in endeavouring to relate the images produced to anatomy and pathology. Most find a period of apprenticeship the easiest way to overcome this problem. The applications of ultrasound to that eminently suitable subject, the young child, continue to increase.
This timely publication allows one to share the experience of pioneers of sonographic examination of infants' hip joints.

The book is essentially a profusely illustrated atlas of the normal and abnormal appearances of the hip joint, with clearly annotated anatomical details. Introductory chapters provide photographic illustration of the correct positioning and scanning techniques, with sections on instrumentation, adjustment, and documentation. The first half of the book is essentially descriptive, in which the spectrum of acetabular dysplasia and hip dislocation is well presented. The second half of the book is mostly concerned with the quantative evaluation of hip sonograms, with associated angular measurements, which Dr Graf in particular has developed.

Not all ultrasonographers would feel inclined to use this technique or abide by the classifications, but the qualitative value of the illustrations in these sections remains useful and informative, and as a practical atlas the work can be commended.

D G SHAW

\section{Correction}

An error occurred in the paper entitled 'Actiological factors in leukaemia and lymphoma', by McKinney. Cartwright, Saiu, et al. 62:279-87.

Throughout this paper, for the term 'common null cell acute lymphoblastic leukaemia' plese read 'common acute lymphoblastic leukacmia'.

This error occurs only in the context of this paper. 